\title{
No effects of habitat, prey abundance and competitor carnivore abundance on fecal cortisol metabolite levels in wildcats (Felis silvestris)
}

\author{
Ana Piñeiro ${ }^{1}$, Isabel Barja ${ }^{1, \star}$, Gracia Patricia Otero², Gema Silván ${ }^{3}$ \& \\ Juan Carlos Illera ${ }^{3}$
}

1) Departamento de Biología, Unidad de Zoología, Universidad Autónoma de Madrid, C/Darwin, 2 , Campus Universitario de Cantoblanco, ES-28049 Madrid, Spain ("corresponding author's: e-mail: isabel.barja@uam.es)

2) Digital Image Processing (DIMAP), ES-28223 Madrid, Spain

3) Departamento de Fisiología (Fisiología Animal), Facultad de Veterinaria, Universidad Complutense de Madrid, ES-28040 Madrid, Spain

Received 6 Mar. 2014, final version received 16 Sep. 2014, accepted 10 Aug. 2014

Piñeiro, A., Barja, I., Otero, G. P., Silván, G. \& Illera, J. C. 2015: No effects of habitat, prey abundance and competitor carnivore abundance on fecal cortisol metabolite levels in wildcats (Felis silvestris). - Ann. Zool. Fennici 52: 90-102.

Conservation physiology is an important tool used to understand how variation in the natural environment can evoke a physiological stress response in free-living animals. The aim of this study was to analyze how fecal cortisol metabolite (FCM) levels vary in response to habitat type, prey abundance and interspecific competition in a free-living population of wildcats in northwest Spain. We collected 110 fresh fecal samples from 25 wildcats along 28 transects between May 2005 and June 2009. To determine habitat characteristics and competing carnivore abundance, we defined 110 circular plots with the fresh wildcat scat at the center. For each plot, we sampled habitat variables, competitor carnivore abundance (pine marten [Martes martes] and red fox [Vulpes vulpes]) and prey abundance (wood mice [Apodemus sylvaticus]). Our results indicate that habitat variables, interference competition and main prey abundance did not significantly affect FCM levels in wildcats.

\section{Introduction}

Abiotic and biotic changes are common in the environment, and animals respond to these changes through temporal variation in their vital rates (Morris \& Doak 2002) and alterations in their physiological responses (Wingfield et al. 1997). Adolph (1956) demonstrated the relationship between physiological regulation and the animal's ability for adapting to new environ- mental conditions. Physiological tools serve as useful diagnostics in conservation physiology (Wingfield et al. 1997, Wikelski \& Cooke 2006, Busch \& Hayward 2009).

Glucocorticoid (GC) levels are used as an indicator of physiological stress (Wingfield \& Romero 2001, Wikeliski \& Cooke 2006). When an animal is subjected to a stressor, the hypothalamus releases corticotropin-releasing hormone $(\mathrm{CRH})$, causing the pituitary to secrete adreno- 
corticotropic hormone (ACTH), which signals the adrenal cortex to release steroid hormones such as GCs to help overcome stressful situations (Sapolsky et al. 2000) and restore homeostasis (Möstl \& Palme 2002). However, prolonged exposure to stressors causes chronic increase in GC levels and leads to detrimental 'chronic stress' (Romero 2004). Chronic stress causes depressed immune responses, reduces reproductive success, suppresses growth, or decreases survival, and therefore, it can negatively affect individual fitness (Romero 2004).

Fecal glucocorticoid metabolite quantification is a non-invasive tool that provides important information about endocrine status (Young et al. 2004, Palme 2005, Sheriff et al. 2011). This method is particularly useful because samples can be obtained without disturbing the animals (Wasser et al. 2000) and it has been previously used in wildcat (Piñeiro et al. 2012). Thus, analyzing fecal glucocorticoids is a valuable method for studying potential stressors that may affect carnivores under natural conditions (Barja et al. 2007, Piñeiro et al. 2012).

Habitat conditions may affect GC levels. It is well known that habitat quality can influence the physiology and individual fitness of vertebrates (Huey 1991). In addition, habitat change is considered a stressor in free-living vertebrates (Wingfield et al. 1998). Therefore, in the context of landscape ecology, physiological responses can be used to guide conservation and habitat restoration efforts (Wikelski \& Cooke 2006). However, few studies have explored the links between physiological responses and habitat spatial patterns (Ellis et al. 2012). In mammals, most studies have examined the effect of habitat quality on the levels of GC (e.g., kit fox [Vulpes macrotis] and coyote [Canis latrans]: Nelson 2005; wolf [Canis lupus]: Barja et al. 2007; black howler monkey [Alouatta pigra]: Martínez-Mota et al. 2007; caribou [Rangifer tarandus caribou] and moose [Alces alces]: Wasser et al. 2011).

Food limitation may also elicit physiological stress responses in vertebrates (Ellis et al. 2012), affecting survival and limiting growth and fecundity (Boutin 1990). Nutritional stress is defined as a negative physiological and/or behavioural state resulting from the sub-optimal quantity or quality of food available to an animal (Trites \& Donnelly 2003). Thus, an increase in GC levels may be attributable to low forage quality (Taillon \& Côté 2008) and/or low food abundance (Foley et al. 2001).

The effects of interspecific competition may also evoke a physiological stress response (Nelson 2005). There are two types of interspecific competition: exploitation competition and interference competition (Birch 1957). However, there are few studies considering interference competition as a stressor (e.g., habitat segregation: Nelson 2005). The competitive exclusion principle predicts that two species with identical niches cannot coexist indefinitely (Gause 1934). However, subsequent studies revealed that the coexistence of similar carnivore species could be facilitated by different strategies, such as habitat use variation, temporal segregation, or trophic changes (Bonesi et al. 2004, Barrientos \& Virgós 2006, Hass 2009). In this sense, competition between species would be higher when species whose geographic areas overlap show similar body size and feeding habits (Donadio \& Buskirk 2006).

In Atlantic climatic regions, wildcats (Felis silvestris) and their competitors, such as the pine marten (Martes martes) select forest habitats (Barja 2005b, Klar et al. 2008, Pereboom et al. 2008). The red fox (Vulpes vulpes), which is also a competitor of wildcats, is considered a habitat generalist (Lucherini et al. 1995). Wildcat is a territorial species (Sunquist \& Sunquist 2002), and its habitat use is often associated with prey availability (Lozano et al. 2006). In the north Iberian Peninsula, rodents are the main prey of wildcats and pine martens (Rosellini et al. 2008, Piñeiro \& Barja 2011), and they are also frequently consumed by the red fox (Carvalho $\&$ Gomes 2004). The feeding strategy adopted by wildcat and pine marten is like facultative specialist predators, although the trophic diversity of the pine marten is higher than that of the wildcat (Rosellini et al. 2007, Piñeiro \& Barja 2011). On the other hand, the red fox is considered a trophic generalist (Jędrzejewski \& Jędrzejewska 1992), so the considerable overlap between wildcats and foxes does not necessarily mean high competitive interaction (Carvalho \& Gomes 2004). Considering results of the studies mentioned above, the wildcat and the pine 


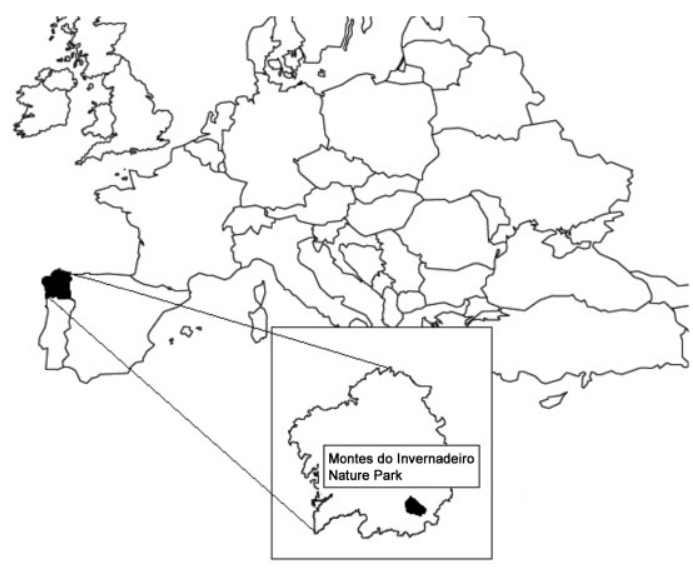

Fig. 1. Location of the study area, Montes do Invernadeiro Nature Park, on the Iberian Peninsula.

marten compete through interference competition that involves direct negative interactions, whereas the wildcat and the red fox are exploitative competitors and show indirect negative interactions. Therefore, interference competition and low prey abundance may act as stressors in wildcat populations.

Thus, in the present study, we examined the physiological stress response induced by the following stressors in free-living wildcats: habitat type, prey availability and interspecific competition with the pine marten and the red fox. We predicted that wildcats would show higher FCM levels in habitats with lower prey abundance and increased interference competition.

\section{Material and methods}

\section{Study area}

We conducted the study in Montes do Invernadeiro Nature Park, a protected area of 5722 ha, situated in the northwest Iberian Peninsula. The park is located in a transition zone between the Eurosiberian and Mediterranean biogeographical regions (Castroviejo 1977). This study area is mountainous and comprises three landscape systems: scrubland, deciduous forests, and pine forests. Scrubland vegetation is the principal habitat and is formed mainly by Spanish heath (Erica australis), prickled broom (Pterospartum tridentatum), and yellow rock rose (Halim- ium lasianthum). Patches of deciduous forests are mainly located in valleys and watercourses, where English oak (Quercus robur), white birch (Betula celtiberica) and English holly (Ilex aquifolium) are commonly found. Patches of Scots pine plantations (Pinus sylvestris) scattered throughout the study area occupy the remaining land (Pulgar 2004) (Fig. 1).

\section{Transect survey to collect fresh fecal samples}

Wildcats, pine martens, and red foxes use forest roads for traveling and frequently defecate on them as a way of visual-scent marking (Robinson \& Delibes 1988, Barja et al. 2001, Barja 2005a, Piñeiro \& Barja 2012). Thus, we surveyed on foot 300-m-long transects along forest roads in order to collect fresh wildcat fecal samples from which we quantified FCM levels. Furthermore, in these transects, we recorded the number of pine marten and red fox scats to estimate their abundances. To increase the probability of locating scats from different individuals and to minimize pseudoreplication, transects were separated by a distance of $700 \mathrm{~m}$. The transect surveys were conducted seasonally between May 2005 and June 2009 in 25 Universal Transverse Mercator (UTM) cells of $1 \mathrm{~km}^{2}$ each and a total of 28 transects were surveyed monthly. The length of transects was based on individual genotyping performed in our study area, in which we identified 25 wildcat genotypes ( 6 males and 19 females), with mean home ranges of 953.7 ha for males and 301.2 ha for females (Piñeiro $\&$ Barja 2012). Transects were uniformly distributed throughout the study area, and a total area of $311.2 \mathrm{~km}^{2}$ was surveyed. Morphological characteristics (size and shape) were used to distinguish the scats of the studied species (wildcat, pine marten and red fox) and other carnivores in the study area (weasels [Mustela nivalis], stoats [Mustela erminea], and wolves). For each pine marten or red fox scat, we registered the following data: species, date and UTM coordinates.

The transects were surveyed between sunrise and three hours thereafter to collect fresh wildcat fecal samples because microbial action and exposure to environmental conditions (such 
as heavy rain or snow) can alter the levels of cortisol metabolites (Millspaugh \& Washburn 2003). We considered that a scat was fresh when they had a moist layer of mucus, a strong smell and no signs of dehydration (Liu et al. 2006). For each fresh scat, we mixed the total fecal sample since GCs are not always distributed equally throughout the scat (Barja et al. 2012). We always sampled $10 \mathrm{~g}$ of fresh scat to standardize the sampling procedure. All fecal samples were immediately frozen at $-20{ }^{\circ} \mathrm{C}$ for subsequent laboratory analysis. We recorded the date and UTM coordinates for each fresh wildcat fecal sample. We could not sex all fecal samples because DNA is highly degraded in feces.

\section{Habitat characteristics and competitor abundance}

In order to determine habitat characteristics and the abundance of competing carnivores, we defined 110 circular plots, $1 \mathrm{~km}$ in diameter, with the fresh wildcat scat samples at the center (Fig. 2). For each plot we analyzed the following variables: (1) pine marten and red fox abundance (by counting their scats), (2) wood mouse abundance, (3) total area of deciduous forests, pine forests, scrublands, and pastureland (pastures and crops), (4) total area occupied by water (rivers and creeks), and (5) total area occupied by forest roads.

Habitat variables, and water and forest road areas in each plot were quantified using a geographical information system (GIS) database (scale 1:25 000) on topographic maps (from Sistema de Información de Ocupación del Suelo en España). Location data were translated into the GIS (gvSIG 1.9. Conselleria d'Infrastrucutures i Transport, Generalitat Valenciana; available at http://www.gvsig.org/web/).

\section{Prey abundance}

Wood mice constitute the principal prey of wildcats in the study area (Piñeiro \& Barja 2011). Thus, to determine its abundance, we conducted seasonal live trappings at the same time that the transects were surveyed, in the three most rep- resentative habitats of the study area (deciduous forests, pine forests, and scrubland) (Fig. 2A). In each habitat, the traps were placed in three UTM cells separated by a mean distance of $3 \mathrm{~km}$. In each cell, we placed 25 Sherman traps in a grid, where traps were located $10 \mathrm{~m}$ apart (total effort, 4725 trap nights). Traps remained open $24 \mathrm{~h}$ for three consecutive days and they were checked every $12 \mathrm{~h}$. All the traps were baited with bread soaked in oil and insulated from the heat and cold with raw wool. To allow the identification of each individual for later recapture and thus, avoiding pseudoreplication in the abundance data, the captured animals were marked with a non-toxic, waterproof, colored spray paint at different parts of the body. For each captured animal, the colored painting was placed at a different place. Thus, the capture-recapture technique gave us the minimum number of wood mice in each sampled cell. After handling, wood mice were released at the point of capture.

To estimate wood mouse abundance in each plot, we considered its predominant habitat and the season and year in which each fresh wildcat scat was located. Thus, for each plot, we extrapolated the number of wood mice captured at the nearest trapping cell. In addition, we considered that the trapping cell had the same predominant habitat as the plot and that the captures were performed in the same season and year as the collection of the wildcat fecal sample.

\section{Specific origin and individual genotyping}

Based on their shape and size, it is difficult to differentiate between wildcat feces and those of feral cats or hybrids. Therefore, it is necessary to use a multi-evidence approach including DNA methods, as reported Davison et al. (2002), but see also Lozano et al. (2013). In the present study, species identification through molecular analysis was conducted using a sub-sample of feces to determine the species of origin and the reliability of the data obtained. In addition, individual genotyping was performed, according to the method used by Oliveira et al. (2009), to determine the minimum number of wildcats from which the scats originated; this information was necessary to determine whether the number of 

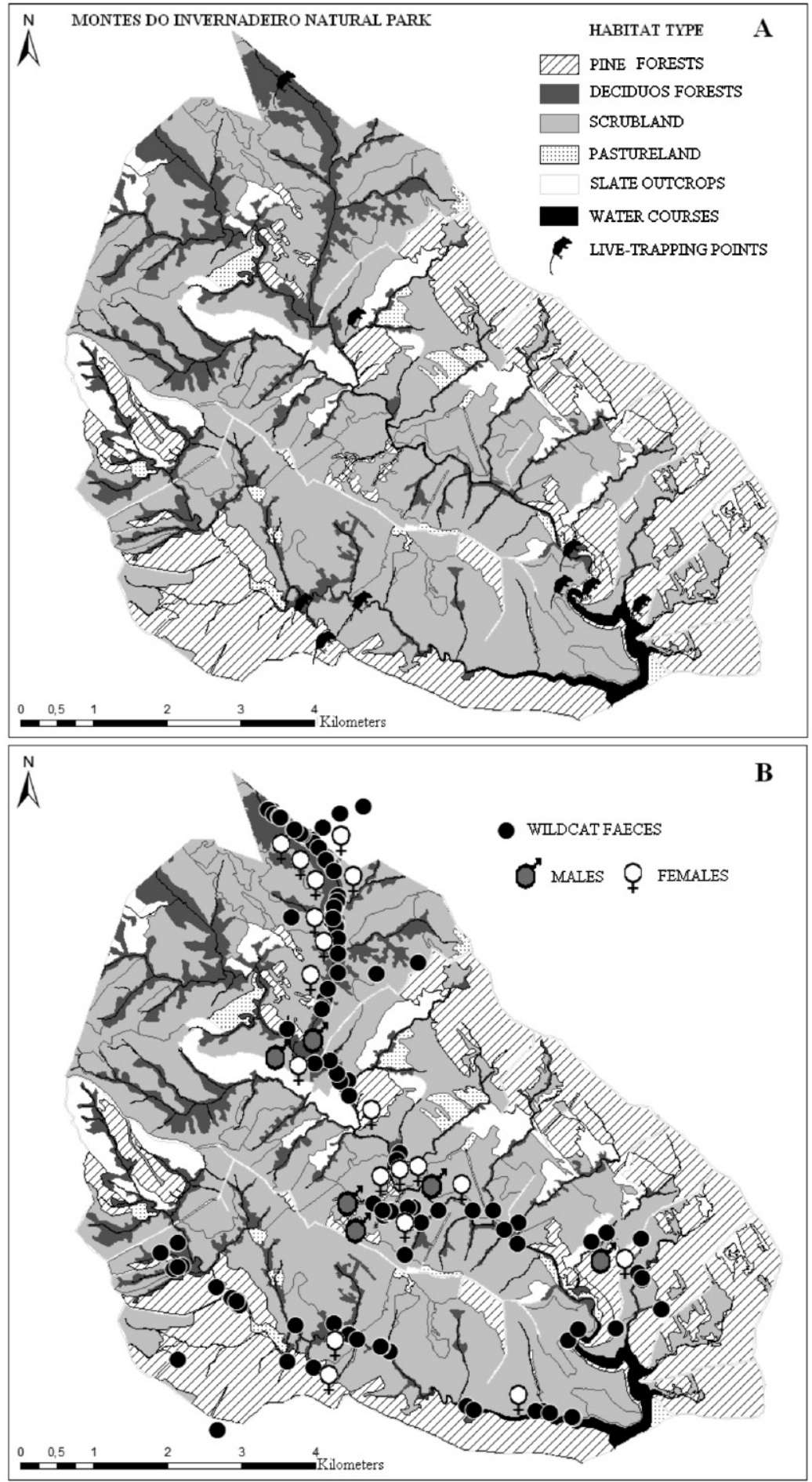

Fig. 2. (A) Predominant habitats and trapping points of wood mice in the study area. (B) Distribution of fresh wildcat feces collected and the wildcat male and female individuals genetically identified in the study area.

detected scats was representative of the wildcat population. To perform species identification and individual genotyping, we collected a total of 41 fresh fecal samples spread evenly throughout the study area. A total of 25 wildcat genotypes were identified (6 males and 19 females) (Fig. 2B). 
DNA extraction from the fecal samples was performed using salting-out and phenol-chloroform extraction (Sambrook et al. 1989). We assessed individual multilocus genotypes by using 12 neutral unlinked microsatellites that were isolated and characterized in the domestic cat (Oliveira et al. 2008). Polymerase chain reaction (PCR) amplification of individual microsatellites was performed, as described by Randi et al. (2001). Allele frequencies, standard diversity indices, and observed (HO) and expected (HE) heterozygosities for each locus and population were calculated using GENETIX 4.05 (Belkhir et al. 1996-2004).

To measure the reliability of the scat identifications, we used the Reliotype software (Miller et al. 2002), which was used to assess the reliability of the multilocus genotypes and to estimate the number of replicates necessary to obtain a genotype with $95 \%$ confidence. The GIMLET software (Valiere 2002) was used to estimate error rates and construct consensus genotypes from the genotyping replicates. Moreover, it was used to regroup identical genotypes from different scat samples and determine parentage between individuals (kinship).

\section{Quantification of fecal cortisol metabolites}

Cortisol metabolites were extracted using previously established methods for similar carnivore species (Brown et al. 1994, 1996, Young et al. 2004, Barja et al. 2007). The efficiency of extraction was tested by the addition of a radiolabelled hormone (3H-cortisol, 4000-8000 dpm, ICN, California, USA) to a parallel set of fecal samples. 3H-cortisol evaluates both extraction efficiency and recovery of the technique used. We followed the techniques proposed by others authors (Brown et al. 1996, Young et al. 2004; and J. Brown unpubl. data). This parameter demonstrates the efficiency of the extraction procedure used, as well as the recovery, since there are several extraction protocols for glucocorticoid metabolites in feces. Schatz and Palme (2001) found differences between sexes in the percentages of radiolabelled cortisol excreted in feces of domestic cats (females: $85 \%$, males:
$78.6 \%$ ). These authors stated that the significance of this observation needs further evaluation. Young et al. (2004) performed a validation experiment on domestic cats, cheetah, and clouded leopard (Neofelis nebulosa). Then they evaluated results by using a similar cortisol EIA to the one we used our analyses, and concluded that this EIA is suitable for monitoring adrenocortical activity in felids.

The cortisol metabolite concentrations in the fecal extracts were determined using an enzyme immunoassay. Hormone concentrations were calculated using software developed for this technique (ELISA-AID, Eurogenetic, Belgium). Standard dose-response curves were constructed by plotting the binding percentage $-B / B_{0} \times 100$ - against the standard hormone concentrations added, where $B / B$ o is the relationship between the amount of bound enzyme conjugate to the concentration/mass of the standard/unknowns added.

The mean recovery percentages from fecal extracts were $95 \%$ for high concentrations and $98 \%$ for low concentrations. Parallel displacement curves were obtained by comparing serial dilutions of pooled fecal extracts with the standard curves. The results showed that both curves were parallel. Intra- and inter-assay coefficients of variation were calculated by assaying 10 replicates of a pooled fecal sample in the same assay and 10 replicates of the same sample in 10 consecutive assays. The percentages recovered for high and low concentrations were $4.5 \%$ and $7.5 \%$, respectively. For each sample, cortisol metabolite concentrations were expressed in nanograms per gram (ng $\mathrm{g}^{-1}$ ) of dry feces. All feces collected were first dried in a conventional oven at $50{ }^{\circ} \mathrm{C}$ for several hours, following the procedures described by other authors (Brown et al. 1996, Young et al. 2004; and J. Brown unpubl. data).

\section{Statistical analyses}

Since the quantitative variables were not normally distributed (Shapiro-Wilk test), we $\log (x+1)$-transformed these variables prior to analyses to ensure normality and homoscedasticity. To avoid multicollinearity (Graham 2003), we performed a principal component analysis 
(PCA) on the basis of correlation matrices to reduce the number of habitat variables. Variables included in the PCA were the following: deciduous forest, pine forest, scrubland and pastureland, water, and forest road area.

We used a generalized linear model (GLM) to evaluate the predictor variables (PCA factors, pine marten abundance, red fox abundance, and wood mouse abundance) that influenced FCM levels in wildcats (response variable). In order to select the best model, we ranked the alternative models based on relative differences in the second order Akaike's Information Criterion (AIC). We calculated Akaike's weight $\left(w_{i}\right)$, which is interpreted as the weight of evidence that a model is the best approximating model (Burnham \& Anderson 2002). We used the sum of Akaike weights $\left(\Sigma w_{i}\right)$ for each variable to rank variables by their importance (Burnham \& Anderson 2002); variables with the highest weight $\left(\Sigma \omega_{\mathrm{m}}=0.95\right)$ being more important than the other variables. Selection of candidate models followed the rule in which $\Delta i \leq 2$ has substantial empirical support, where $\Delta i$ is the AIC difference between model $i$ and the single best model (the model with the smallest AIC value): $\Delta i=\mathrm{AIC}_{i}-\mathrm{AIC}_{\min }$ (Burnham \& Anderson 2002). Also, Burnham et al. (2011) following Sugiura (1978) and Hurvich and Tsai (1989) recommend that when sample sizes are small, as they often are in behavioral studies, it is better to use $\mathrm{AIC}_{\mathrm{c}}$ instead of AIC. Finally, we checked whether the best models (within $2 \mathrm{AIC}_{\mathrm{c}}$ units from the top-ranked model) improved in terms of AIC with interactions fitted.

Test results whose $p<0.05$ were considered statistically significant. All analyses were performed with STATISTICA ver. 8.0 software for Windows (StatSoft Inc, Tulsa, USA).

\section{Results}

Pine marten and red fox scats were detected in 86 of 110 circular plots containing wildcat scats; the scat number per circular plot ranged from 1 to 7 for both species. We captured a total of 232 wood mice during the study, and their abundance varied between 1 and 25 individuals per circular plot (mean $\pm \mathrm{SD}=8.9 \pm 5.8$ ).
The habitat variable PCA produced two orthogonal factors, which explained $55.1 \%$ of the total variance. The first principal component (factor 1) described open areas with high forest road area and low herb cover (water area, forest roads and scrubland areas). The second principal component (factor 2) represented habitats with high herb cover (deciduous forest, pastureland and pine forest area) (Table 1).

The levels of fecal cortisol metabolites were analyzed in 110 fresh fecal samples of wildcats. The GLM showed that the factors considered did not significantly affect the FCM levels (Table 2). A total of 31 occurrence models were possible with the variables considered, but only 12 models were regarded as plausible $(\Delta \mathrm{AIC} \leq 2)$ (Table 2). Factor 1, pine marten abundance, and factor 2 had the most weight in explaining FCM concentrations (Table 3). By contrast, the abundance of wood mice and red foxes had lower relevance in the occurrence models (Table 3). The relations between wildcat prey abundance or competitor species abundance (pine marten and red fox) and cortisol metabolite concentrations were not significant (Fig. 3). Furthermore, wildcats did not show an increase in FCM concentrations in relation to habitat type, water, and forest road areas.

\section{Discussion}

The results of our study indicate that the abundance of carnivore competitors (here the pine marten and red fox), and the abundance of

Table 1. Results of the principal component analysis performed with variables used to describe the wildcat habitat. Asterisks $\left(^{*}\right)$ indicate significant correlations ( $p$ $<0.05$ ) between the variables and factors.

\begin{tabular}{lcc}
\hline Variables & Factor 1 & Factor 2 \\
\hline Water area & 0.18 & $-0.80^{*}$ \\
Forest road area & $-0.66^{\star}$ & $0.21^{*}$ \\
Scrubland area & -0.04 & $0.66^{*}$ \\
Deciduous forest area & $-0.67^{\star}$ & 0.01 \\
Pastureland area & $0.59^{*}$ & $0.41^{*}$ \\
Pine forest area & $0.77^{\star}$ & $-0.33^{*}$ \\
Eigenvalue & 2.07 & 1.24 \\
Explained variance percenrtge & 34.48 & 20.60
\end{tabular}


wood mice did not significantly affect the FCM levels in the wildcat. Cortisol metabolite levels in wildcat feces collected in pine forests did not increase significantly. However, an increase in cortisol metabolite levels in wildcats in pine forests was probably because this is one of the preferred habitats of the pine marten (Barja 2005b). These species could compete for the use of space and trophic resources (rodents), which are more scarce in pine forests than in the other habitat types studied here (A. Piñeiro \& I. Barja unpubl. data). In addition, snow depth in pine forests is greater (Dötterer \& Bernhart 1996), which hin- ders wildcats when hunting for rodents (Corbett 1979). However, studies with wildcats shows that the species avoid areas with snow (Liberek 1999) and avoids mature forests (Corbett 1979).

The importance of scrubland providing wildcats with cover for shelter and its richness in prey has been shown in several studies (Lozano et al. 2003, Thiel 2005, Monterroso et al. 2009). In the study area, scrubland is the habitat that harbors a greater abundance of wildcats' main prey, small mammals (A. Piñeiro \& I. Barja unpubl. data). Thus, we predicted that in scrubland wildcats would show high FCM levels since competition

Table 2. Relative contribution of each variable in the best models that explain the fecal cortisol metabolite concentrations (response variable) in wildcats. Number of parameters used ( $k$ ), Akaike information criterion (AIC), difference between each selected model and the best model ( $\triangle \mathrm{AIC})$, log-likelihood ratio and their respective $p$ values.

\begin{tabular}{|c|c|c|c|c|c|}
\hline Models & $k$ & $\mathrm{AIC}$ & $\Delta \mathrm{AIC}$ & Log-likehood ratio & $p$ \\
\hline Factor 1 & 1 & 186.83 & 0 & 0.20 & 0.65 \\
\hline Pine marten abundance & 1 & 186.90 & 0.06 & 0.14 & 0.71 \\
\hline Factor 2 & 1 & 186.92 & 0.09 & 0.11 & 0.73 \\
\hline Red fox abundance & 1 & 186.96 & 0.12 & 0.08 & 0.78 \\
\hline Wood mouse abundance & 1 & 187.04 & 0.20 & 0.00 & 0.95 \\
\hline Pine marten abundance + Factor 2 & 2 & 188.05 & 1.22 & 0.99 & 0.61 \\
\hline Factor $1+$ Factor 2 & 2 & 188.72 & 1.88 & 0.32 & 0.85 \\
\hline Red fox abundance + Factor 1 & 2 & 188.76 & 1.92 & 0.28 & 0.87 \\
\hline Pine marten abundance + Factor 1 & 2 & 188.77 & 1.93 & 0.27 & 0.87 \\
\hline Pine marten abundance + Red fox abundance & 2 & 188.82 & 1.98 & 0.22 & 0.89 \\
\hline Wood mouse abundance + Factor 1 & 2 & 188.82 & 1.99 & 0.22 & 0.90 \\
\hline Red fox abundance + Factor 2 & 2 & 188.85 & 2.01 & 0.19 & 0.91 \\
\hline
\end{tabular}

Table 3. Results of the generalized linear models with predictors (Factor 1 and Factor 2: principal component analysis factors, WMA: wood mouse abundance, PMA: pine marten abundance, RFA: red fox abundance) explaining the variation in fecal cortisol metabolite levels. $\triangle A I C_{c}$ represents the difference between $\mathrm{AIC}_{c}$ of the model under consideration (model $i$ ) and the one with the lowest $\mathrm{AIC}_{\mathrm{c}}$ value of all models, at the top of the table, being $\mathrm{AIC}=\mathrm{AIC}$ $+[2 K(K+1)] /(n-K-1)$, where $K$ is the total number of estimable parameters in the model. AIC $\mathrm{C}_{\mathrm{c}}$ weights indicate the strength of evidence that the selected model is the best; $w_{i}$ ranges from 0 to 1 and provides an effective way to scale and interpret the $\Delta i$ (Burnham and Anderson 2002). The evidence ratio is calculated as $w_{0} / w_{p}$, where $w_{0}$ is the generalized Akaike weight of model 1, and $w_{i}$ is the generalized Akaike weight of model $i$.

\begin{tabular}{lcccc}
\hline Model & AIC & $\Delta \mathrm{AIC}_{\mathrm{c}}$ & $\mathrm{AIC}_{\mathrm{c}}$ weights & Evidence ratio \\
\hline Factor 1 & 186.83 & 0 & 0.14 & - \\
PMA & 186.90 & 0.06 & 0.13 & 0.97 \\
Factor 2 & 186.92 & 0.09 & 0.13 & 0.98 \\
RFA & 186.96 & 0.12 & 0.13 & 0.98 \\
WMA & 187.04 & 0.20 & 0.12 & 0.96 \\
PMA + Factor 2 & 188.05 & 1.37 & 0.07 & 0.60 \\
Factor 1 + Factor 2 & 188.72 & 2.04 & 0.05 & 0.72 \\
RFA + Factor 1 & 188.76 & 2.07 & 0.05 & 0.98 \\
PMA + Factor 1 & 188.77 & 2.08 & 0.05 & 0.99 \\
PMA + RFA & 188.82 & 2.14 & 0.05 & 0.97 \\
WMA + Factor 1 & 188.82 & 2.14 & 0.05 & 0.99 \\
\hline
\end{tabular}



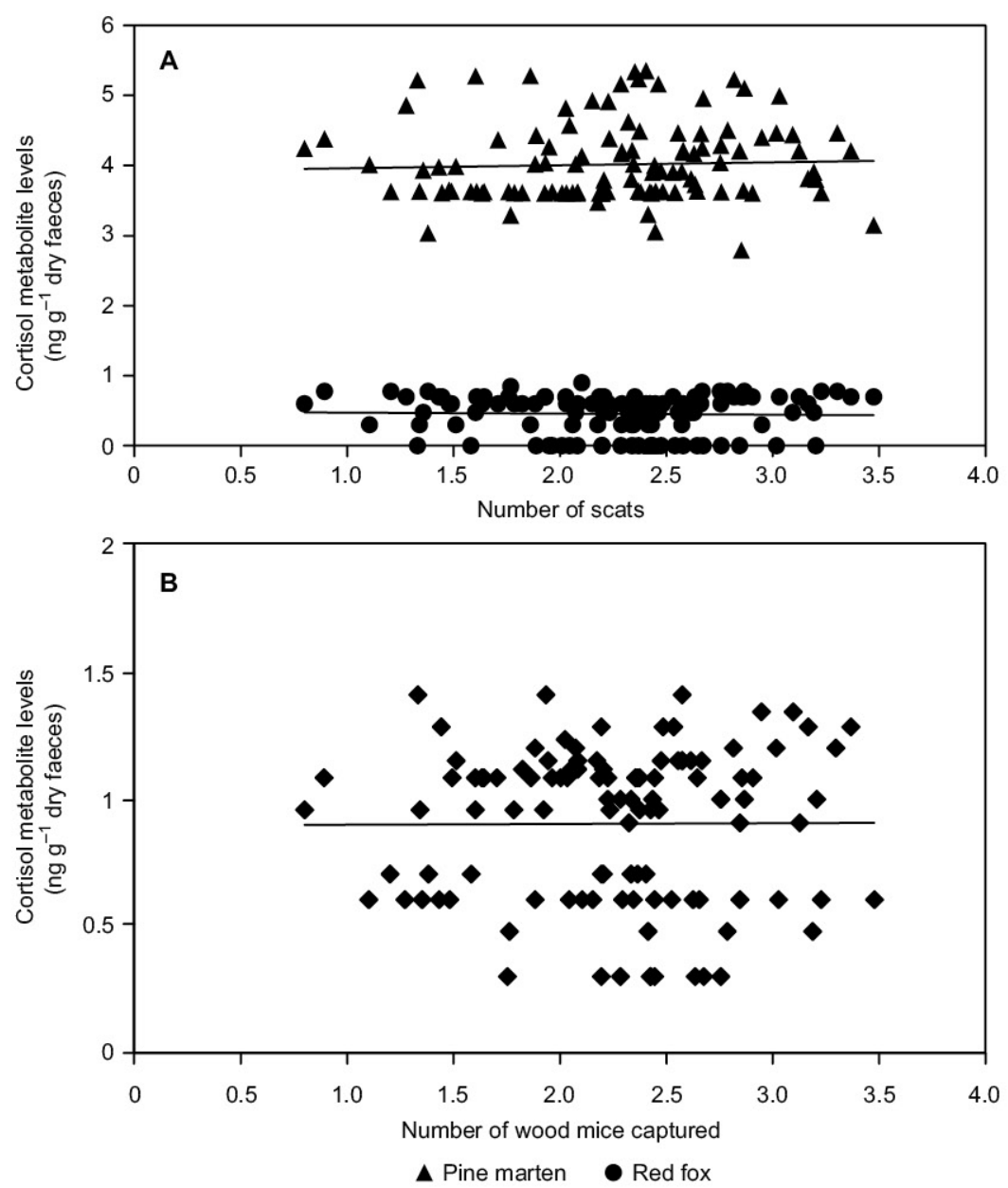

Fig. 3. Comparison of the concentrations of fecal cortisol metabolites $[\log (x$ +1 )-transformed] according to $(\mathbf{A})$ the pine marten and red fox abundances, and (B) wood mice abundance in each plot. for the main trophic resources could be higher at the intraspecific but also at the interspecific levels because pine martens also seem to hunt frequently in this habitat type (Clevenger 1994). However, we found that scrublands had no statistically significant effect on cortisol metabolite levels in wildcats.

Frequent use of pasture and crop areas by wildcats has been shown in different studies (Easterbee et al. 1991, Lozano et al. 2003); these areas are mainly used during the night for foraging and hunting (Thiel 2005). Other studies indicated that in these open areas wildcats are exposed to humans (Monterroso et al. 2009). However, the results of this study did not concur with those conducted with felids in captivity (Montanha et al. 2009) and with that of a study conducted with pine martens in the same study area (Barja et al. 2007), in which human presence was considered a stressor. Thus, the increase in FCM levels associated with this habitat may be because these areas are used for hunting but, because wildcats are nocturnal hunters, the effects of the presence of human were too low to show a significant physiological stress response.

The wildcat feces collected from circular plots where deciduous forests and watercourses were the predominant habitats did not show lower cortisol metabolite concentrations than those collected from plots with other predominant habitats. In the study area, deciduous forests are located in valleys with rivers and permanent streams. Deciduous forests provide shelters (Klar et al. 2008), e.g., tree cavities, which can be used as dens (Stahl \& Artois 1991). In addition, many studies have shown the importance of watercourses in habitat selection for wildcats (Lozano et al. 2003, Barja \& Bárcena 2005, 
Klar et al. 2008, Jerosch et al. 2010) because of the higher abundance of small mammals (hUallacháin \& Madden 2011).

Wildcats use forest roads for travelling and leaving their territorial signals (Corbett 1979, Piñeiro \& Barja 2012). Thus, forest roads may act as travel corridors, especially during times of heavy snowfall (Woods \& Munro 1996). Also, forest roads could serve as hunting areas, because roads are a suitable habitat for wood mice (Bellamy et al. 2000). However, activity patterns of wildcats at forest roads overlap with the activity patterns of the pine marten and red fox (Corbett 1979, Clevenger 1993, Doncaster \& Macdonald 1997). Therefore, when there are few forest roads, the probability of encounters with competitors such as pine martens and red foxes is greater and therefore, it was expected that cortisol metabolite levels in feces collected in these zones would be greater too. Nevertheless, forest roads were abundant in our study and also used by tourists visiting the park, so, small mammal abundance in this habitat was expected to be low. Thereby, the use of forest roads as hunting zones does not seem to be sufficiently stressful for wildcats to evoke physiological changes.

In addition to habitat variables, we showed that the abundance of carnivore competitors, such as the pine marten, did not act as an acute stressor in wildcats. The pine marten is a carnivore with slightly smaller body size than that of the wildcat, but with similar prey and habitat preferences (Barja 2005b, Rosellini et al. 2008). Therefore, we expected that an increase in FCM levels in wildcats might be related to their defense of resources against a competitor. Donadio and Buskirk (2006) argued that similarity in body size leads competitors to seek similar prey, which increases the likelihood of interference encounters. Furthermore, in our study area, both carnivores (wildcat and pine marten) prey more on wood mice during periods when rodents are easier to capture, but not a too abundant trophic resource (Rosellini et al. 2008, Piñeiro \& Barja 2011). This could explain why the presence of a competitor, such as the pine marten, does not significantly increase fecal cortisol metabolite levels in wildcats.

In the present study, the abundance of red foxes seemed to have had no influence on cor- tisol metabolite levels in wildcats. This may be attributable to the generalistic character of the red fox, both in diet (Jedrzejewski \& Jędrzejewska 1992) and habitat selection (Lucherini et al. 1995); this leads to lower competition between the two species. The abundance of wood mice also did not greatly affect cortisol metabolite levels. These results are consistent with those of a previous study conducted in the same area, where it was found that the consumption of wood mice depended on their ease of capture and not on their availability in the wildcat territory (Piñeiro \& Barja 2011).

To the best of our knowledge, this is the first report showing evidence of no effects of habitat type, prey abundance and competitor carnivore abundance on fecal cortisol metabolite levels in wildcats being a significant contribution to the knowledge of environmental factors that can affect physiological stress responses in wild carnivores. Since hormone levels in wild animals can be influenced by a wide range of environmental factors, additional research is needed in order to better understand how animal populations react to ecological factors and natural disturbances.

\section{Acknowledgements}

The authors thank the Nature Conservation Service of Ourense (Regional Government of Galicia) for providing permits required to conduct this study in the Montes do Invernadeiro Nature Park, especially to Víctor Manuel Gil. This research was undertaken with permission from the Xunta Galicia wildlife authority (letters of 18/04/05, 18/09/06, 13/07/07). Thanks are due to Centro de Investigação em Biodiversidade e Recursos genéticos (CIBIO, Portugal) for conducting the molecular work. We would like to thank to Álvaro Navarro-Castilla for his generous help reviewing this manuscript. The authors are also grateful to gamekeepers Ricardo Prieto, Tomás Pérez, Paco Barja and Antonino Núñez who kindly provided us logistical assistance during fieldwork. This paper is a contribution to the projects CAM-UCM no. 920694, Universidad Complutense de Madrid and CCG10-UAM/AMB-5325; DGUI of the Comunidad de Madrid and Universidad Autónoma de Madrid.

\section{References}

Adolph, E. F. 1956: General and specific characteristics of physiological adaptations. - American Journal of 
Physiology 184: 18-28.

Barja, I. 2005a: Patrones de marcaje con heces por la marta europea (Martes martes) en el noroeste de España: Importancia para su estudio. - Galemys 17: 123-134.

Barja, I. 2005b: Winter distribution of European pine marten Martes martes scats in a protected area of Galicia, Spain. - Mammalia 69: 435-438.

Barja, I. \& Bárcena, F. 2005: Distribución y abundancia de gato montés (Felis silvestris) en el parque natural Os Montes do Invernadeiro (Galicia, NO de España): factores de hábitat implicados y relación con la presencia de zorro y marta. - Galemys 17: 29-40.

Barja, I., de Miguel, F. J. \& Bárcena, F. 2001: Distribución espacial de los excrementos de zorro rojo (Vulpes vulpes Linnaeus 1758) en los Montes do Invernadeiro (Ourense). - Galemys 13: 171-178.

Barja, I., Escribano, G., Lara, C., Virgós, E., Benito, J. \& Rafart, E. 2012: Non-invasive monitoring of adrenocortical activity in European badgers (Meles meles) and effects of sample collection and storage on faecal cortisol metabolite concentrations. - Animal Biology 62: 419-432.

Barja, I., Silván, G., Rosellini, S., Piñeiro, A., González-Gil, A., Camacho, L. \& Illera, J. C. 2007: Stress physiological responses to tourist pressure in a wild population of European pine marten. - Journal of Steroid Biochemistry and Molecular Biology 104: 136-142.

Barrientos, R. \& Virgós, E. 2006: Reduction of potential food interference in two sympatric carnivores by sequential use of shared resources. - Acta Oecologica 30: 107-116.

Belkhir, K., Borsout, P., Goudet, J., Chikhi, L. \& Bonhomme, F. 1996-2004: Genetix, logiciel sous Windows ${ }^{T M}$ pour la génétique des populations. - Laboratoire Génome et Population, Université de Montpellier, Montepellier.

Bellamy, P. E., Shore, R. F., Ardeshir, D., Treweek, J. R. \& Sparks, T. H. 2000: Road verges as habitat for small mammals in Britain. - Mammal Review 30: 131-139.

Birch, L. C. 1957: The meaning of competition. - American Naturalist 91: 5-18.

Bonesi, L., Chanin, P. \& Macdonald, D. W. 2004: Competition between Eurasian otter Lutra lutra and American mink Mustela vison probed by niche shift. - Oikos 106: 19-26.

Boutin, S. 1990. Food supplementation experiments with terrestrial vertebrates: patterns, problems, and the future. - Canadian Journal of Zoology 68: 203-220.

Brown, J. L., Wasser, S. K., Wildt, D. E. \& Graham, L. H. 1994: Comparative aspects of steroid hormone metabolism and ovarian activity in felids, measured noninvasively in feces. - Biology of Reproduction 51: 776-786.

Brown, J. L., Wildt, D. E., Wielebnowski, N., Goodrowe, K. L., Graham, L. H., Wells, S. \& Howard, J. G. 1996: Reproductive activity in captive female cheetahs (Acinonyx jubatus) assessed by faecal steroids. - Journal of Reproduction and Fertility 106: 337-346.

Burnham, K. P. \& Anderson, D. R. 2002: Model selection and multimodel inference. A practical information-theoretic approach. - Springer, New York.

Burnham, K. P., Anderson, D. R. \& Huyvaert, K. P. 2011: AIC model selection and multimodel inference in behav- ioral ecology: some background, observations, and comparisons. - Behavioral Ecology and Sociobiology 65: 23-35.

Busch, D. S. \& Hayward, L. S. 2009: Stress in a conservation context: a discussion of glucocorticoid actions and how levels change with conservation-relevant variables. Biological Conservation 142: 2844-2853.

Carvalho, J. C. \& Gomes, P. 2004. Feeding resource partitioning among four sympatric carnivores in the PenedaGerês National Park (Portugal). - Journal of Zoology 263: 275-283.

Castroviejo, S. 1977: Estudio sobre la vegetación de la Sierra del Invernadeiro (Ourense). - ICONA, Madrid.

Clevenger, A. P. 1993: Sign surveys as an important tool in carnivore conservation research and management programmes. - In: Seminar on the Management of Small Populations of Threatened Mammals: 44-55. Council of Europe, Sofia, Bulgaria.

Clevenger, A. P. 1994: Habitat characteristics of Eurasian pine martens in an insular Mediterranean environment. - Ecography 17: 257-263.

Corbett, L. K. 1979: Feeding ecology and social organization of wildcats (Felis silvestris) and domestic cats (Felis catus) in Scotland. - Ph.D. thesis, University of Aberdeen.

Davison, A., Birks, J. D. S., Brookes, R. C., Braithwaite, T. C. \& Messenger, J. E. 2002: On the origin of faeces: Morphological versus molecular methods for surveying rare carnivores from their scats. - Journal of Zoology 257: 141-143.

Donadio, E. \& Buskirk, S. W. 2006: Diet, morphology, and interspecific killing in Carnivora. - American Naturalist 167: 524-536.

Doncaster, C. P. \& Macdonald, D. W. 1997: Activity patterns and interactions of red foxes (Vulpes vulpes) in Oxford city. - Journal of Zoology 241: 73-87.

Dötterer, M. \& Bernhart, F. 1996: The occurrence of wildcats in the southern Swiss Jura Mountains. - Acta Theriologica 41: 205-209.

Easterbee, N., Hepburn, L. V. \& Jefferies, D. J. 1991: Survey of the status and distribution of the wildcat in Scotland, 1983-1987. - Nature Conservancy Council for Scotland, Edinburgh.

Ellis, R. D., McWhorter, T. J. \& Maron, M. 2012: Integrating landscape ecology and conservation physiology. - Lanscape Ecology 27: 1-12.

Foley, C. A. H., Papageorge, S. \& Wasser, S. K. 2001: Noninvasive stress and reproductive measures of social and ecological pressures in free-ranging African elephants (Loxodonta africana). - Conservation Biology 15: 1134-1142.

Gause, I. 1934: The struggle for existence. - Williams and Wilkins, Baltimore.

Graham, M. H. 2003: Confronting multicollinearity in ecological multiple regression. - Ecology 84: 2809-2815.

Hass, C. C. 2009: Competition and coexistence in sympatric bobcats and pumas. -Journal of Zoology 278: 174-180.

hUallacháin, D. Ó. \& Madden, D. 2011: Impact of riparian vegetation structure on small mammal communities. - In: hUallacháin, D. Ó. \& Finn, J. (eds.), Proceedings 
of Teagasc Biodiversity conference. Conserving Farmland Biodiversity: Lessons learned and future prospects, 25-26 May 20011: 96-97. Teagasc, Head Office, Oak Park, Carlow.

Huey, R. 1991: Physiological consequences of habitat selection. - American Naturalist 137: 91-115.

Hurvich, C. M. \& Tsai, C.-L. 1989: Regression and time series model selection in small samples. - Biometrika 76: 297-307.

Jędrzejewski, W. \& Jędrzejewska, B. 1992: Foraging and diet of the red fox Vulpes vulpes in relation to variable food resources in Białowieża National Park, Poland. - Ecography 15: 212-220.

Jerosch, S., Götz, M., Klar, N. \& Roth, M. 2010: Characteristics of diurnal resting sites of the endangered European wildcat (Felis silvestris silvestris): Implications for its conservation. - Journal for Nature Conservation 18: 45-54.

Klar, N., Fernández, N., Kramer-Schadt, S., Herrmann, M., Trinzen, M., Büttner, I. \& Niemitz, C. 2008: Habitat selection models for European wildcat conservation. Biological Conservation 141: 308-319.

Liberek, M. 1999: Eco-etologie du chat sauvage Felis s. silvestris, Schreber 1777 dans le Jura Vaudois (Suisse). Influence de la couverture neigeuse. - Ph.D. thesis. Université Neuchatel, Neuchatel.

Liu, J., Chen, Y., Guo, L., Gu, B., Liu, H., Hou, A., Liu, X., Sun, L. \& Liu, D. 2006: Stereotypic behavior and faecal cortisol level in captive giant pandas in relation to environmental enrichment. - Zoological Biology 25: 445-459.

Lozano, J., Virgós, E., Malo, A. F., Huertas, D. L. \& Casanovas, J. G. 2003: Importance of scrub-pastureland mosaics on wild-living cats occurrence in a Mediterranean area: implications for the conservation of the wildcat (Felis silvestris). - Biodiversity Conservation 12: 921-935.

Lozano, J., Moleón, M. \& Virgós, E. 2006: Biogeographical patterns in the diet of the wildcat, Felis silvestris Schreber, in Eurasia: factors affecting the trophic diversity. Journal of Biogeography 33: 1076-1085.

Lozano, J., Virgós, E. \& Cabezas-Díaz, S. 2013: Monitoring European wildcat populations using scat surveys in central Spain: are population trends related to wild rabbit dynamics or to landscape features? - Zoological Studies 52: 16.

Lucherini, M., Lovari, S. \& Crema, G. 1995: Habitat use and ranging behavior of the red fox Vulpes vulpes in a Mediterranean rural area: is shelter availability a key factor? - Journal of Zoology 237: 577-591.

Martínez-Mota, R., Valdespino, C., Sánchez-Ramos, M. A. \& Serio-Silva, J. C. 2007: Effects of forest fragmentation on the physiological stress response of black howler monkeys. - Animal Conservation 10: 374-379.

Miller, C. R., Joyce, P. \& Waits, L. 2002: Assessing allelic dropout and genotype reliability using maximum likelihood. - Genetics 160: 357-366.

Millspaugh, J. J. \& Washburn, B. E. 2003: Within-sample variation of fecal glucocorticoid measurements. - General and Comparative Endocrinology 132: 21-26.
Montanha, J. C., Silva, S. L. \& Boere, V. 2009: Comparison of salivary cortisol concentrations in jaguars kept in captivity with differences in exposure to the public. Ciência Rural 36: 1745-1751.

Monterroso, P., Brito, J. C., Ferreras, P. \& Alves, P. C. 2009: Spatial ecology of the European wildcat in a Mediterranean ecosystem: dealing with small radio-tracking datasets in species conservation. - Journal of Zoology 19: 1-9.

Morris, W. F. \& Doak D. F. 2002: Quantitative conservation biology: theory and practice of population viability analysis. - Sinauer Associates, Massachusetts.

Möstl, E. \& Palme, R. 2002: Hormones as indicators of stress. - Domestic Animal Endocrinology 23: 67-74.

Nelson, J. L. 2005: Effects of varying habitats on competition between endangered San Jaoquin kit foxes (Vulpes macrotis mutica) and coyotes (Canis latrans). - M.Sc. thesis, Montana State University, Bozeman.

Oliveira, R., Godinho, R., Randi, E. \& Alves, P. C. 2008: Hybridization versus conservation: are domestic cats threatening the genetic integrity of wildeats (Felis silvestris silvestris) in Iberian Peninsula? - Philosophical Transactions of the Royal Society of London B 363: 2953-2961.

Oliveira, R., Castro, D., Godinho, R., Luikart, G. \& Alves, P. C. 2009: Species identification using a simple SSCP analysis of a nuclear gene: application to carnivores of southwest Europe. - Conservation Genetics 11: 1023-1032.

Palme, R. 2005: Measuring fecal steroids-guidelines for practical application. Bird hormones and bird migrations: analyzing hormones in droppings and egg yolks and assessing adaptations in long-distance migration. - Annals of the New York Academic of Sciences 1046: $75-80$.

Pereboom, V., Mergey, M., Villerette, N., Helder, R., Gerard, J. F. \& Lodé, T. 2008: Movement patterns, habitat selection, and corridor use of a typical woodland-dweller species, the European pine marten (Martes martes), in fragmented landscape. - Canadian Journal of Zoology 86: 983-991.

Piñeiro, A. \& Barja, I. 2011: Trophic strategy of the wildcat Felis silvestris in relation to seasonal variation in the availability and vulnerability to capture of Apodemus mice. - Mammalian Biology 76: 302-307.

Piñeiro, A. \& Barja, I. 2012: The plant physical features selected by wildeats as signal posts: An economic approach to fecal marking. - Naturwissenschaften 99: 801-809.

Piñeiro, A., Barja, I., Silván, G. \& Illera, J. C. 2012: Effects of tourist pressure and reproduction on physiological stress response in wildcats: management implications for species conservation. - Wildlife Research 39: 532-539.

Pulgar, I. 2004: Guía da flora do Parque Natural Montes do Invernadeiro. - Consellería de Medio Ambiente, Xunta de Galicia, Ourense, Spain.

Randi, E., Pierpaoli, M., Beaumont, M., Ragni, B. \& Sforzi, A. 2001: Genetic identification of wild and domestic cats (Felis silvestris) and their hybrids using bayesian clustering methods. - Molecular Biology and Evolution 
1818: 1679-1693.

Robinson, I. H. \& Delibes, M. 1988: The distribution of faeces by the Spanish lynx (Felis pardina). - Journal of Zoology 216: 577-582.

Romero, M. L. 2004: Physiological stress in ecology: lessons from biomedical research. - Trends in Ecology and Evolution 19: 249-255.

Rosellini, S., Barja, I. \& Piñeiro, A. 2007: Distribución y hábitos alimenticios de la marta (Martes martes) en el Parque Natural Os Montes do Invernadeiro (Galicia, NO de España). - Galemys 19: 99-114.

Rosellini, S., Barja, I. \& Piñeiro, A. 2008: The response of European pine marten (Martes martes L.) feeding to the changes of small mammal abundance. - Polish Journal of Ecology 56: 497-504.

Sambrook, E., Fritsch, F. \& Maniatis, T. 1989: Molecular cloning. - Cold Spring Harbour Press, New York.

Sapolsky, R. M., Romero, L. M. \& Munck, A. U. 2000: How do glucocorticoids influence stress responses? Integrating permissive, suppressive, stimulatory, and preparative actions. - Endocrine Review 21: 55-89.

Schatz, S. \& Palme, R. 2001: Measurement of faecal cortisol metabolites in cats and dogs: an non-invasive method for evaluating adrenocortical function. - Veterinary Research Communications 25: 271-287.

Sheriff, M. J., Dantzer, B., Delehanty, B., Palme, R. \& Boonstra, R. 2011: Measuring stress in wildlife: techniques for quantifying glucocorticoids. - Oecologia 166: 869-887.

Stahl, P. \& Artois, M. 1991: Status and conservation of the wild cat (Felis silvestris) in Europe and around the Mediterranean Rim. - Council of Europe, France.

Sunquist, M. \& Sunquist, F. 2002: Wild cats of the world. The University of Chicago Press, Chicago.

Sugiura, N. 1978: Further analysis of the data by Akaike's information criterion and the finite corrections. - Communications in Statistics - Theory and Methods 7: 13-26.

Taillon, J. \& Côté, S. D. 2008: Are faecal hormone levels linked to winter progression, diet quality and social rank in young ungulates? An experiment with white-tailed deer (Odocoileus virginianus) fawns. - Behavioral Ecology and Sociobiology 10: 1591-1600.

Thiel, C. 2005: Spacing patterns and habitat use of wildcats in the Eifel. - In: Symposium: Biology and Conservation of the European wildcat (Felis silvestris silvestris) Germany
January 21st-23rd 2005, Abstracts: 21. Öko-Log.

Trites, A. W. \& Donnelly, C. P. 2003: The decline of Steller sea lions in Alaska: a review of the nutritional stress hypothesis. - Mammalian Biology 33: 3-28.

Valiere, N. 2002: GIMLET: a computer program for analysing genetic individual identification data. - Molecular Ecology Notes 2: 377-379.

Wasser, S. K., Keim, J. L., Taper, M. L., \& Lele, S. R. 2011: The influences of wolf predation, habitat loss, and human activity on caribou and moose in the Alberta oil sands. Frontiers in Ecology and the Environment 9: 546-551.

Wasser, S. K., Hunt, K. E., Brown, J. L., Cooper, K., Crockett, C. M., Bechert, U., Millspaugh, J. J., Larson, S. \& Monfort, S. L. 2000: A generalized fecal glucocorticoid assay for use in a diverse array of non-domestic mammalian and avian species. - General and Comparative Endocrinology 120: 260-275.

Wikelski, M. \& Cooke, S. J. 2006: Conservation physiology. - Trends in Ecology and Evolution 21: 38-46.

Wingfield, J. C. \& Romero, L. M. 2001: Adrenocortical responses to stress and their modulation in free-living vertebrates. - In: McEwen, B. S. (eds.), The endocrine system, coping with the environment: neural and endocrine mechanisms: 211-234. Handbook of Physiology. Oxford University Press, Oxford.

Wingfield, J. C., Breuner, C., Jacobs, J. D., Lynn, S., Maney, D., Ramenofsky, M. \& Richardson, R. 1998: Ecological bases of hormone-behavior interactions: the emergency life history stage. - American Zoology 8: 191-206.

Wingfield, J. C., Hunt, K., Breuner, C., Dunlap, K., Fowler, G. S., Freed, L. \& Lepson, J. 1997: Environmental stress, field endocrinology, and conservation biology. In: Clemmons, J. R. \& Buchholz, R. (eds.), Behavioral approaches to conservation in the wild: 95-131. Cambridge University Press, Cambridge.

Woods, J. G. \& Munro, R. H. 1996: Roads, rails and the environment: wildlife at the intersection in Canadas western mountains. - In: Evink, G. L., Garrett, P., Zeigler, D. \& Berry, J. (eds.), Proceedings of the Transportation related Wildlife Mortality Seminar: 47-54. Florida Department of Transportation, Florida.

Young, K. M., Walker, S. L., Lanthier, C., Waddell, W. T., Monfort, S. L. \& Brown, J. L. 2004: Noninvasive monitoring of adrenocortical activity in carnivores by faecal glucocorticoid analyses. - General and Comparative Endocrinology 137: 148-165. 